BULLETIN Bulletin hispanique

HispaniQuE Université Michel de Montaigne Bordeaux

120-1 | 2018

Varia

\title{
Un montón de maneras de conceptualizar la cantidad
}

la persistencia conceptual en los cuantificadores binominales

Un tas de façons de conceptualiser la quantité : la persistance conceptuelle dans les quantificateurs binomiaux

Heaps of ways of conceptualizing quantity: the conceptual persistance in the binomial quantifiers

\section{Katrien Verveckken y Nicole Delbecque}

\section{OpenEdition}

Journals

Edición electrónica

URL: https://journals.openedition.org/bulletinhispanique/5544

DOI: 10.4000/bulletinhispanique.5544

ISSN: 1775-3821

Editor

Presses universitaires de Bordeaux

Edición impresa

Fecha de publicación: 30 junio 2018

Paginación: 123-146

ISBN: 979-10-300-0298-0

ISSN: 0007-4640

Referencia electrónica

Katrien Verveckken y Nicole Delbecque, «Un montón de maneras de conceptualizar la cantidad», Bulletin hispanique [En línea], 120-1 | 2018, Publicado el 01 enero 2022, consultado el 08 enero 2022. URL: http://journals.openedition.org/bulletinhispanique/5544 ; DOI: https://doi.org/10.4000/ bulletinhispanique.5544 


\title{
Un montón de maneras de conceptualizar la cantidad: la persistencia conceptual en los cuantificadores binominales
}

\author{
Katrien Verveckken y Nicole Delbecque \\ KU Leuven - Belgique
}

L'objectif est d'illustrer la productivité de la construction binominale quantitative du type [un N1 de N2], p.ex. un montón de años 'un tas d'années'. L'hypothèse est qu'à chaque $\mathrm{N} 1$ correspond une conceptualisation particulière des entités constituantes (N2, p.ex. años) en raison de la persistance conceptuelle de la signification lexicale du nom quantifieur (N1, p.ex. montón).

Mots-clés: sémantique cognitive, noms quantifieurs, persistance conceptuelle, images conceptuelles, cohérence.

El objetivo es ilustrar la productividad de la construcción binominal cuantitativa del tipo [un N1 de N2], e.g. un montón de años. La hipótesis es que a cada N1 corresponde una conceptualización propia de las entidades constituyentes (N2, e.g. años) debido a la persistencia conceptual del significado léxico del nombre cuantificador (N1, e.g. montón).

Palabras-claves: semántica cognitiva, nombres cuantificadores, persistencia conceptual, imágenes conceptuales, coherencia.

The aim of the article is to illustrate the productivity of the binominal quantifier construction of the type [un N1 de N2] 'a N1 of N2', e.g. un montón de años 'a heap of years'. The hypothesis is that to each quantifying noun corresponds a proper conceptualization of the constituting entities (N2, e.g. años) due to the conceptual persistence of N1's lexical meaning (N1, e.g. montón).

Keywords: cognitive semantics, quantifying nominals, conceptual persistence, conceptual images, coherence. 


\section{Planteamiento}

El objetivo de este artículo es dar cuenta de la variación en el paradigma de los nombres cuantificadores (cf. Bosque 2007: 191-196). Tomando como puntos de partida la iconicidad del orden lineal y la persistencia conceptual, el análisis desarrolla la hipótesis siguiente: cada nombre cuantificador aporta su propia conceptualización de la cantidad, de forma que al cambiar de nombre cuantificador se produce algún deslizamiento semántico.

Los nombres cuantificadores (NC) disponen de un potencial cuantitativo al lado de su significado léxico original. Entre los ejemplos emblemáticos figuran contenedores (brazada), configuraciones (montón, racimo, pila), colectivos (hatajo, tropel) e incluso conceptos abstractos como barbaridad y horror con tal que entrañen una inferencia de escala por vía de extensiones metonímicas o metafóricas ${ }^{1}$. Al entrar en las construcciones binominales cuantitativas ${ }^{2}$ (e.g. [1]), pasan a ser expresiones de cuantificación. Constan de un determinante (por defecto, indefinido), el NC (o N1) y un sintagma preposicional introducido por de que designa las entidades constituyentes (N2).

(1) un montón $\mathrm{N}_{\mathrm{N} 1}$ de gente $\mathrm{N}_{\mathrm{N} 2}$, un horror $\mathrm{N}_{1}$ de $\operatorname{mosquitos}_{\mathrm{N} 2}$, un aluvión $\mathrm{N}_{\mathrm{N} 1}$ de llamadas $_{\mathrm{N} 2}$, etc.

Estudios previos (Verveckken 2012b; Delbecque \& Verveckken 2014) señalan que la construcción binominal cuantitativa puede dar lugar a tres usos distintos. En el uso literal de núcleo, como en (2), N1 activa su significado léxico original: remite a una determinada configuración física concreta, y constituye el núcleo semántico y sintáctico de la construcción.

(2) El médico Manuel Muro, bata blanca y mirada franca, me habla desde el otro lado de una pila de radiografías amontonadas. (CREA)

Además del uso léxico, existen dos usos de tipo funcional en los que N1 deja de ser interpretado literalmente. En el uso cuantificador, como en (3), la cuantificación de $\mathrm{N} 2$ se realiza por metaforización en términos de $\mathrm{N} 1$, o sea, el enunciador invita a comparar la cantidad de llamadas con la imagen conceptual asociada típicamente a N1. Entre los criterios diagnósticos figura la

1. Este análisis no se detiene en los nombres típicamente cuantitativos como mayoría, cantidad, par, kilo, parte, etc. cuyo significado léxico original remite a una determinada cantidad de algo. Huelga decir que nombres cuantificadores como aluvión solo adquieren su interpretación cuantitativa por metaforización.

2. Se opta por las denominaciones 'nombre cuantificador', 'cuantificadores binominales' y 'construcción binominal cuantitativa' en vez de los términos 'sustantivos cuantitativos' y 'construcciones (pseudo)partitivas' utilizados en las gramáticas de referencia (Bosque \& Demonte 1999, RAE 2009). Hay dos razones para ello. Una es que el presente artículo sólo se enfoca en usos característicos de "sustantivos acotadores" y "sustantivos de grupo", dejando a un lado los "sustantivos de medida", el tercer subtipo de sustantivos cuantitativos. La otra razón es que la descripción tradicional de la construcción (pseudo)partitiva presenta varios traslapos formales y/o funcionales con la construcción partitiva y la aposición enfática (Verveckken 2012a: 42-47). 
sustitución por el cuantificador estándar muchola(s): en (3), las autoridades han recibido muchisimas llamadas. En el uso categorizador, ejemplificado en (4) y (5), N1 sigue agrupando el conjunto de N2 como en el uso cuantificador, pero ahora su papel esencial consiste en categorizar N2 en función de la imagen conceptual asociada a N1. Así, el enunciador perfila a los llamados cabritos - sus interlocutores - como un conjunto de imbéciles que no saben pensar ni actuar de manera autónoma. Se puede postular, además, que la categorización opera en dos niveles: en un primer nivel N1 destaca cierta(s) característica(s) de N2 $y$, en un segundo nivel, el conjunto [un N1 de N2] establece una categorización metafórica de una determinada entidad $X$, externa a la construcción binominal cuantitativa; esto explica que se encuentre en posición de predicativo (e.g. apóstrofe en [4], complemento predicativo de la música clásica no era más que en [5]).

(3) La sala del 091, la Guardia Urbana, los servicios de Protección Civil de Barcelona y las redacciones de los diarios ("¿qué ha pasado?») empezaron a recibir un alud de llamadas de ciudadanos preocupados por el intenso temblor que durante casi cinco segundos notaron bajo sus pies. (CREA)

(4) - Dos cosas, por lo menos, debíais aprender de este hecho, hatajo de cabritos. La primera [...] (CREA)

(5) Cuando en mi casa sacábamos el tema de la música, mi madre decía que lo que llaman música clásica no era más que un montón de ruidos insoportables capaces de volver loca a cualquiera. (CREA)

La hipótesis que se desarrolla a continuación se basa en los conceptos de 'persistencia conceptual' e 'iconicidad'. La noción de persistencia conceptual se inspira en la noción de persistencia léxica (Hopper 1991). Dentro del marco de la gramaticalización, significa que en el uso gramaticalizado de una construcción pueden persistir - e incluso ganar en influencia - algunos rasgos léxicos del uso original de la misma. Con respecto al uso sincrónico de los cuantificadores binominales, la persistencia conceptual implica que, en la conceptualización que cada N1 impone a la masa N2, sigue trasluciéndose la imagen conceptual original de $\mathrm{N}^{3}$ (véase también Bosque [2007: 192, 194]). Si bien es semejante la idea subyacente, parece justificado sustituir 'léxica' por 'conceptual'. Como argumento más decisivo se puede aducir que las facetas reflejadas en los usos funcionales o gramaticalizados no suelen coincidir con las facetas perfiladas en las entradas lexicográficas correspondientes. Delbecque $\&$ Verveckken (2014) subrayan que lo que persiste en los usos funcionales consta de una selección de facetas del dominio conceptual del NC y que esta selección varía de un contexto a otro (véase infra, Sección 2). Cabe invocar también el concepto de iconicidad (García 2009). Como es bien sabido, el orden de los

3. Huelga decir que el impacto de la persistencia conceptual en sincronía se motiva por el desarrollo de la construcción; véase Verveckken (2012a) para el análisis diacrónico de los cuantificadores binominales. 
eventos se ve reflejado a menudo en el orden lineal de los elementos lingüísticos (Dirven \& Verspoor 1998: 8) $)^{4}$. Como dentro del sintagma binominal, el N1 viene mencionado y procesado primero, determina la imagen esquemática de la masa. Por su parte, N2 se ajusta al perfil activado previamente por N1, como lo muestra la Figura 1. De ahí que tropel, montón, pila y aluvión vehiculen conceptualizaciones distintas del N2 gente en los ejemplos siguientes5.

(6) El PRÍNCIPE se halla acostado y duerme. Arde la chimenea. Súbitamente irrumpe en su cámara un tropel de gente capitaneado por el propio REY, que se cubre la cabeza con un casco y lleva debajo del jubón de raso negro una coraza; la espada en la mano y el gesto altivo y regio. (CREA)

(7) Usted mismo ha mencionado antes los liberales, después está la ultra derecha, la ultra izquierda, los anarquistas, un montón de gente. (CREA)

(8) Aproveché para mirar mi agenda, cosa que rara vez hago y, como siempre que la examino, me di cuenta de que había un montón de cosas que debía haber hecho esa semana que no hice y una pila de gente a la que debía haber llamado y no llamé, con lo que he quedado fatal para siempre. (CREA)

(9) A partir de las 9.30 de la noche un aluvión de gente importante comienza a invadir la casa. (CREA)

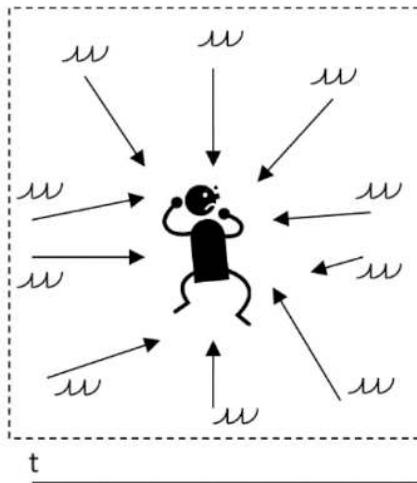

un aluvión

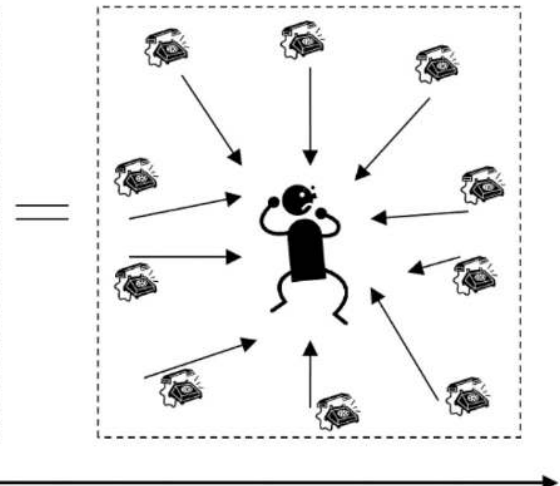

de llamadas

Fig. 1. - La iconicidad del orden lineal en el sintagma binominal [un N1 de N2]. Imagen conceptual de aluvión aplicada a llamadas. Representación visual diseñada por K. Verveckken (2012a).

4. Piénsese en las palabras históricas Veni, vidi, vici de César que dejan de tener sentido al invertir el orden: ${ }^{*}$ Vici, vidi, veni (Dirven \& Verspoor 1998: 8).

5. Como mínimo, en (6), tropel realza la dimensión jerárquica presente en el contexto; en (7), montón señala que las personas forman un conjunto desordenado, reunidas tal cual, mientras que en (8) vienen anotadas en orden cronológico; en (9), aluvión destaca la dinamicidad de la llegada. 
Con el fin de comprobar si hasta los NCs más desemantizados se caracterizan por introducir una cierta imagen conceptual, perfilando las entidades N2 de una manera propia, se ha optado por un análisis de corpus sincrónico. Para una selección de nueve NCs, se han extraído muestras exhaustivas del Corpus de Referencia del Español Actual (CREA) mediante la búsqueda [NC de]. La distribución global se presenta en la Tabla 1.

\begin{tabular}{|c|c|c|c|c|c|c|c|c|c|}
\hline & Alud & Aluvión & Barbaridad & Hatajo & Letanía & Mogollón & Montón & Pila & Racimo \\
\hline CREA & 86 & 150 & 9 & 16 & 26 & 46 & 500 & 80 & 48 \\
\hline
\end{tabular}

Tabla 1. - Distribución global en el corpus analizado 6.

En la presente contribución se postula que la variación paradigmática del NC se explica por su valor pragmático. Si el NC no solo agrupa las entidades N2, sino también permite calificarlas a la luz de la imagen conceptual asociada a $\mathrm{N}^{7}$, los cuantificadores binominales se convierten en cuantificadores expresivos que satisfacen mejor las necesidades del hablante que los cuantificadores canónicos como muchola(s) o los numerales. De ser acertada la hipótesis, incluso los NCs cuasi-sinónimos como el par alud - aluvión evocarán imágenes conceptuales diferentes y se caracterizarán por combinatorias distintas (Sección 2). Al tratarse de cuantificadores expresivos, es previsible que influyan también en la organización informativa y la coherencia textual (Sección 3).

\section{IMÁGENES CONCEPTUALES Y ESQUEMATIZACIÓN}

En semántica cognitiva, el significado se considera emergente (Paradis 2011). Significa que los elementos lingüísticos solo adquieren su interpretación final en contexto. Parafraseando, se distingue entre la estructura esquemática por un lado, y los mecanismos de conceptualización que operan en ella por otro. El análisis semántico del corpus sincrónico revela, en efecto, que los rasgos semánticos perfilados pueden variar de un contexto a otro. Si bien es cierto que, en los ejemplos (10) y (11), aluvión conceptualiza, respectivamente, los curas y las llamadas como un conjunto de entidades dinámicas que de repente surgen todas a la vez de la nada y así abruman a los oyentes (10) y a los médicos

6. En el caso de montón - el N1 más frecuente -, se ha extraído una muestra representativa de 500 ejemplos

7. Huelga decir que la dimensión de categorización añadida a la cuantificación por el fenómeno de la persistencia conceptual no equivale al uso plenamente categorizador del NC, ilustrado en (4) y (5), en que la categorización es definitoria de la función del NC dentro del sintagma binominal, y el NC tiende por lo mismo a presentar un alto grado de persistencia conceptual. En los usos gramaticalizados del NC, la categorización adicional debida a la persistencia conceptual es lo que distingue los NCs de los cuantificadores propiamente dichos. Los cuantificadores binominales ocupan pues una posición intermedia en el continuo entre la expresión de cantidad y la expresión de calidad: permiten cuantificar un conjunto de entidades, atribuyéndoles al mismo tiempo cierta(s) característica(s) específica(s). 
(11), resulta que en (10) es particularmente prominente el carácter repentino y nuevo de la intervención de los curas, mientras que en (11) destaca el carácter sorpresivo de la cantidad de llamadas. Aunque lo repentino, lo nuevo y lo sorpresivo son todas facetas conceptuales que pertenecen al semantismo original de aluvión, los indicios contextuales y la escena evocada realzan las dos primeras en (10) y la tercera en (11).

(10) 'Ya no era sólo el padre Antonio el que hablaba descaradamente de "libertad", de amor, de caridad y de pureza de intenciones. De repente, un aluvión de curas nuevos planteaban soluciones nunca oídas hasta aquellos momentos. (CREA)

(11) A las 9 horas, tres médicos del cuerpo de sanidad militar comenzaron a atender las seis líneas habilitadas del teléfono 91-395-54-85. Sin embargo, el aluvión de llamadas desbordó todas las previsiones, por lo que Defensa reforzó el servicio con otros siete facultativos más, (...). (CREA)

A la luz de esto parece justificado distinguir entre una estructura esquemática que constituye el potencial semántico de los NCs y la interpretación que los NCs reciben en contextos específicos. De aquí en adelante se denomina imagen conceptual el significado esquemático de los NCs. La imagen conceptual se concibe como un espacio mental (Fauconnier \& Turner 1998: 137) que consiste en un conjunto de facetas conceptuales susceptibles de presentar distintos grados de esquematización. La idea es que el contexto discursivo particular del $\mathrm{NC}$ y la escena evocada co-determinan qué (conjunto de) faceta(s) se perfila(n) en ocurrencias específicas.

Ahora bien, para cada NC del corpus es posible destilar la imagen conceptual combinando tres fuentes de información complementarias: (a) la intuición de hablantes nativos ${ }^{8}$; (b) las entradas de diccionarios de referencia, en particular el DRAE, el DUE y el CLAVE ${ }^{9}$ y (c) el análisis semántico del corpus. Cabe insistir en que en las imágenes conceptuales solo se han retenido las facetas que se manifiestan de forma muy recurrente bajo la forma de indicios contextuales o que caracterizan sistemáticamente la escena evocada.

Hasta el NC más común, a saber, montón, relativamente pobre a nivel léxico, deja entrever facetas de su semantismo original. Las entradas lexicográficas coinciden en describirlo como un conjunto de cosas, de forma o tamaño indeterminados, acumuladas o puestas sin orden unas encima de otras en una configuración típicamente cónica. Le reconocen además un uso cuantitativo que definen simplemente como equivalente a un número considerable o gran

8. Les agradecemos a Lydia Fernández Pereda, Marían Gomez Castejón, Pedro Gras Manzano, Nuria Herrera Coronas, Daniel Michaud Maturana, María Sol Sansiñena Pascual e Ingeborg Verelst-Pérez la amabilidad con que discutieron y revisaron repetidamente la interpretación de los ejemplos del corpus.

9. Los acrónimos remiten al Diccionario de la lengua española (RAE 2001), al Diccionario de Uso del Español (Moliner 2008) y al Clave-Diccionario de USO Del Español (Maldonado González 1999). 
cantidad de cosas. El análisis semántico muestra, sin embargo, que los usos cuantitativos de montón reflejan varias facetas de su semantismo original.

Como se ilustra a continuación, la faceta más recurrente es la 'acumulación'. Al igual que los componentes de un montón literal (e.g. las hojas en un montón de papel), las entidades N2 cuantificadas por montón de casi siempre se perfilan como un conjunto de entidades acumuladas. En (12), el interlocutor ha permanecido callado durante un largo intervalo. En la medida que hay acumulación previa, también puede destacar la 'contigüidad espaciotemporal' entre las entidades N2: en (13), las personas cuantificadas se han reunido aquella tarde en aquel sitio para observar los chimpancés. La faceta más abstracta o esquemática que se puede derivar de la acumulación inherente es la idea de que las entidades N2 pertenecen a la 'misma clase o categoría': en (14), el motivo para considerar a los escritores como un conjunto se debe buscar en el gerundio narrando la situación muy verídicamente y sacándose unas pelas. Como se ve en (15), también se acude fácilmente a montón como NC para introducir enumeraciones. Otra faceta relacionada a la acumulación previa es la 'falta de distinción' o el efecto de 'homogeneización', ya que en los montones literales (cf. supra, las entradas lexicográficas), los componentes son puestos unos encima de otros sin orden. Así, en (16), los indicios contextuales señalados en bastardilla ilustran que el conjunto absorbe la individualidad y la identidad de las entidades N2.

(12) Llevas un montón de tiempo sin dar ni clavo, podría haber dicho también en el mismo tono reprobatorio. (CREA)

(13) Era un domingo por la tarde y decidí invertir un poco de mi tiempo en una rápida visita al parque. Recuerdo que había un montón de gente viendo los chimpancés, yo me coloqué detrás. (CREA)

(14) Psicólogos, sociólogos, científicos, más la sabiduría popular y las tertulias de la radio abarrotadas de listillos y famosos dando su versión del puzzle, dando su opinión sobre la incompatibilidad de los sexos. Más un montón de escritores narrando la situación muy verídicamente y sacándose unas pelas. (CREA)

(15) Se ven muchas cosas desde aquí. Hay un montón de estrellas; la osa mayor, las siete hermanas... ¡La luna! (CREA)

(16) Cuando intento pensar en lo sucedido antes de aquel día, todo se me junta en la memoria como un confuso montón de gestos y rostros y lugares, sin acciones, ni formas, ni perspectivas, en que es dificil identificar y distinguir los matices. (CREA)

Además del conglomerado de facetas basadas en la 'acumulación', la imagen conceptual de montón presenta otro conglomerado que gira esencialmente en torno a la 'falta de orden o estructura'. Como se desprende de la descripción 
lexicográfica, la falta de estructura o el desorden están asociados a montones literales y siguen trasluciéndose en muchos ejemplos cuantitativos, como en (16)y (17). De ahí es sólo un pequeño paso hacia la 'falta de claridad acerca de la identidad y/o cantidad exacta'. Al enunciador de (18) no le importa la identidad de los camareros, solo recuerda que hubo tantos que era difícil llevar la cuenta; al enunciador de (19) le da igual tanto el número como la índole de las razones posibles, indica antes que nada que no cree en la superstición de lo amarillo. Otra faceta inferida de la falta de estructura por extensión metonímica es la 'casualidad' o el carácter aleatorio de la acumulación: en (20), es como si las personas estuvieran presentes por casualidad, en (21), la relativa señala que las tonterías se le ocurrieron accidentalmente al enunciador.

(17) Nuestro libro iba ganando páginas, pero había que estructurarlo de alguna manera. Hasta aquel momento teníamos un montón de citas dispersas, además de la fábula cruel de la sábana y la medusa, la sospecha razonable de que fue un pez quien inventó las orejas, y el relato costumbrista de unos floristas enamorados que follaban con gran escándalo. (CREA)

(18) En la comida, ni primero ni segundo, pero sus fritos y sus guisos calientes, fiambres, de todo, las cosas más buenas que tú te puedas calculá y un montón de camareros p'arriba y p'abajo, luego te cuento la que se formó con los camareros. (CREA)

(19) Es raro, ¿̇verdad?, porque en el mundo del flamenco hay mucha superstición. Mira, cuando bailo sólo pienso en que todo salga bien. Me pueden salir las cosas mal porque me duelan los pies, el estómago o por un montón de cosas más, pero no porque lleve algo amarillo. (CREA)

(20) La entrevista con Shultz tuvo lugar en la suite del hotel y no sé muy bien por qué estuvimos presentes un montón de gente: el presidente, el ministro, Juan Antonio Yánéz y yo, Chencho Arias, Santi Salas y Javier Solana. (CREA)

(21) Tengo previsto sacar un libro, Un millón de cosas, que, como su propio nombre indica, se trata de un montón de tonterías que se me han ocurrido. (CREA)

$\mathrm{Al}$ inventariar las facetas conceptuales observadas, consta que la imagen conceptual de montón presenta dos propiedades claves, a saber, la 'acumulación' y la 'falta de estructura'. Ambas facetas pueden manifestarse de forma más velada o abstracta. La Figura 2 da una visión sinóptica de los grados de esquematización distinguibles en la imagen conceptual. Precisamente en tal esquematización estriba el carácter gradual de la persistencia conceptual. Cabe insistir también en que las facetas no se excluyen mutuamente: como se ve en (16), un montón de N2 puede perfilarse como un conjunto homogéneo y desordenado a la vez. 


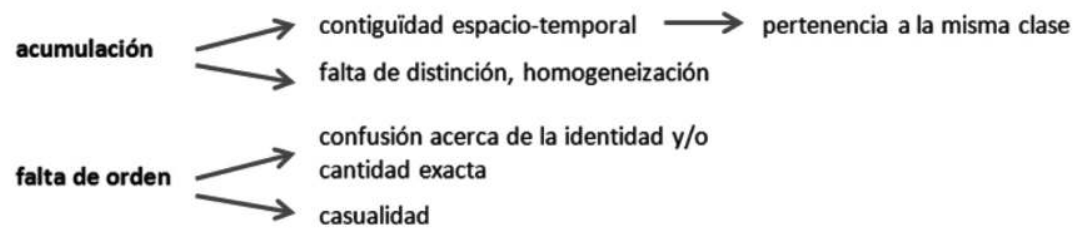

Fig. 2. - Imagen conceptual de montón de como cuantificador. Esquematización propuesta por las autoras.

Con el fin de comprobar el impacto de la persistencia conceptual, el apartado siguiente (2.1) indaga en la alternancia entre los NCs cuasi-sinónimos alud y aluvión. De ser acertada la hipótesis del mantenimiento de imágenes conceptuales propias, la alternancia paradigmática entre alud y aluvión debería dar lugar a deslizamientos semánticos que pueden ser muy sutiles y se reflejan en las preferencias combinatorias. El apartado (2.2) se detiene brevemente en los reflejos formales de la persistencia conceptual en general.

\subsection{Recibir un alud o un aluvión de críticas}

Tanto alud como aluvión pertenecen al campo semántico de los fenómenos naturales que escapan al control humano. Mientras que alud remite en general a una gran masa de nieve (a veces de otra materia) que se derrumba de los montes (o de una vertiente) con violencia y estrépito (cf. DRAE), un aluvión es una avenida fuerte de agua. El parentesco etimológico no se desmiente en las imágenes conceptuales respectivas: en los usos cuantitativos, tanto alud como aluvión perfilan un número aplastante de entidades N2 que de repente emergen simultáneamente como si surgieran de la nada. Las más de las veces, la aparición de las entidades N2 ha sido provocada por alguna causa externa y conlleva consecuencias drásticas (al igual que aludes y aluviones literales para las regiones afectadas). De ahí que las entidades N2 se conceptualicen en general como una fuerza antagónica imparable y dinámica, dirigida hacia una sola víctima, como si la inundasen literalmente. En (22), los nuevos negocios y empresarios salen de repente (súbitamente, de repente) e invaden (parecen inundar) el país sorprendido (inesperada floración). Dado que salen en primera plana (relegando a los políticos a las páginas interiores de los periódicos) y contrastan con la situación previa de paro prolongado (un pais tradicionalmente parado), no cabe duda de que la cantidad de empresas nuevas es enorme. En (23) también, los indicios contextuales (repentino e "inundados") realzan la interpretación metafórica de alud. Los productos agrícolas e industriales se perciben como una cantidad grande que, al emerger de repente, sumerge a los agricultores y los empresarios ((no) preparados para competir). El aumento sustancial ha sido provocado por una causa externa (fruto del radical desarme arancelario) y trae consecuencias impactantes. 
(22) Un país tradicionalmente parado, se ponía súbitamente en movimiento y experimentaba en primavera una inesperada floración de tipos y de ideas nuevas, algunas de las cuales madurarán y darán fruto en el otońo e invierno siguientes. Un aluvión de nuevos negocios, y nuevos empresarios, desconocidos meses atrás, parece inundar de repente la escena nacional, relegando a los politicos a las páginas interiores de los periódicos. (CREA)

(23) ¿¿No nos hemos visto “inundados" por un repentino alud de productos agrícolas e industriales, fruto del radical desarme arancelario, ante el que ni nuestros agricultores ni nuestros empresarios estaban preparados para competir? (CREA)

Aunque los contextos de (22) y (23) se parecen mucho -ambos aluden a un desarrollo económico inesperado y extraordinario-, la sustitución de aluvión por alud en (22), respectivamente la de alud por aluvión en (23), suena rebuscada. La razón reside en el carácter más decisivo de alud y el hecho de que en (22) el desarrollo se presente como una coincidencia positiva. En (23), al contrario, la llegada repentina de productos extranjeros dańa la agricultura nacional. Mientras que la imagen de la víctima derrotada se combina fácilmente con la imagen conceptual de alud ((no) preparados para competir), aluvión hace aparecer la entidad afectada como un antagonista capaz de defenderse. De ahí que aluvión no encaje en el contexto de (23).

A título ilustrativo, la Figura 3 reúne las facetas de la imagen conceptual de aluvión observadas en los ejemplos de corpus (véase Verveckken (2012a) para una descripción detallada). Restricciones de espacio impiden comentar las facetas individualmente. Baste decir que, al igual que la imagen esbozada para montón (Figura 2), la de aluvión se caracteriza por permitir varios grados de esquematización. De llegar todas a la vez ('llegada simultánea'), se puede inferir que las entidades originan en puntos de partida distintos ('orígenes distintos'), como en (24). Si la cantidad de N2 surge de repente, no es de extrañar que sorprenda a los participantes afectados ('no esperado'), como en (11). Si la llegada de N2 sorprende, es probable que las entidades N2 sean 'nuevas', como en (10) más arriba. El ejemplo (10) muestra además que la actualización de una determinada faceta (e.g. 'nuevo'), no excluye la actualización de las demás (e.g. 'de repente').

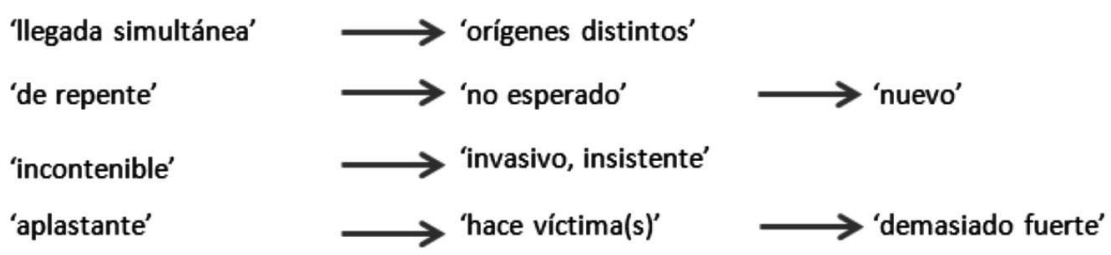

causANTE: aluvión provoca alguna (re)acción/situación causADO: aluvión provocado/motivado por una causa identificable

Fig. 3. - Imagen conceptual de aluvión de como cuantificador.

Niveles de esquematización propuestos por las autoras. 
(24) Como si fuera señal convenida, con la apertura del curso universitario se levantó la veda de los actos culturales. Entre lo que se inauguró y lo que a punto está dentro de unos días, el aluvión de actividades nos llega por distintos frentes, con ímpetu renovado después de la tregua veraniega: exposiciones a lo grande, conciertos, encuentros de teatro, ciclo de conferencias, Congresos internacionales, simposio sobre Murillo... (CREA)

Como veremos a continuación, la imagen conceptual de alud es muy parecida. Las divergencias más llamativas radican esencialmente en (i) el enfoque en las consecuencias drásticas, respectivamente la causa, del súbito aumento de N2; (ii) la orientación y la contundencia de N2; y (iii) la gradualidad del aumento de N2.

La primera diferencia de conceptualización tiene que ver con la importancia del componente causal en las imágenes conceptuales de alud de y aluvión de. Según la perspectiva adoptada, se puede enfocar alternativamente la causa (identificable) que ha provocado el aludlaluvión de N2 o el impacto causado por el aludlaluvión de N2, o ambos a la vez. Ahora bien, mientras que el uso de aluvión suele sugerir que hay una causa identificable (como en (25)), en los contextos de alud (como en (26)) se suele apuntar a la importancia del impacto provocado por la cantidad de N2.

(25) Este cambio provocó en Madrid un aluvión de órdenes de compra y cancelaciones de ventas y llevó al departamento de supervisión de la Sociedad de Bolsas a detener el mercado poco antes de las cinco de la tarde para aliviar la congestión. (CREA)

(26) Pero lo que de verdad hubiera afectado a la estabilidad del país, habría sido el imparable alud de reproches que habría recaído sobre González. (CREA)

Aun más llamativa es la orientación distinta de las fuerzas o entidades dinámicas. Al igual que el agua en aluviones literales, las entidades N2 introducidas por aluvión parecen inundar la víctima desde varios puntos de partida distintos. Con alud, al contrario, provienen de un punto de partida común (cf. la Figura 4). De ahí que un alud de N2 resulte más decisivo que un aluvión de N2. Los ejemplos (27) y (28) ilustran un contexto de uso frecuente de los dos NCs cuasi-sinónimos: por haber tomado medidas radicales o defendido una tesis polémica, un determinado político suscita gran cantidad de críticas. La imagen que se evoca de la oposición, sin embargo, difiere: alud sugiere que actúan en bloque (como en (28)), mientras que aluvión más bien apunta a una diversidad de portavoces y opiniones posiblemente emitidas en momentos diferentes, a las que se puede reaccionar (como en (27)). No significa que en (28), con alud, la oposición conste de un solo partido, ni que las críticas surjan simultáneamente. La cuantificación por alud de sólo tiende a dar de los partidos una visión unificada, dando así a las críticas emitidas una fuerza más contundente.

(27) Diversos portavoces del Ejecutivo subrayaron el compromiso de Bonn de cumplir los acuerdos con los socios europeos y garantizaron la solidez de la moneda única. Scharping volvió a la carga ayer con una entrevista concedida al 
diario "Bild". Ante el aluvión de críticas recibidas, sostuvo que "el SPD debe alertar sobre los posibles riesgos de la introducción de la moneda europea. Ese es nuestro deber". (CREA)

(28) Su discurso, adornado con alabanzas a Irlanda por rechazar el Tratado de Niza y el anuncio de su intención de eliminar los delitos de injurias a la bandera y ataque a la unidad del Estado, desató ayer un alud de críticas en la oposición. (CREA)

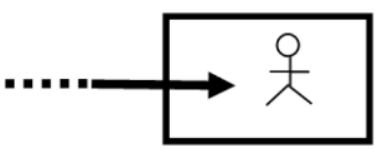

un alud de $\mathrm{N} 2$

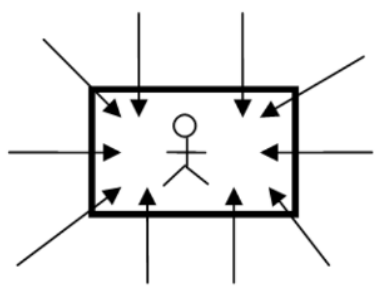

un aluvión de $\mathrm{N} 2$

Fig. 4. - Punto(s) de partida de las entidades N2 con el N1 alud $y$ aluvión. Representación visual originalmente propuesta en Verveckken (2012a).

La tercera divergencia es de índole aspectual. Mientras que en el caso de alud la llegada de las entidades N2 se percibe como un evento puntual, aluvión presenta una dimensión de continuidad. En (29), la decisión del magistrado de anular la rueda de prensa significa que las críticas han alcanzado su objetivo y dejaron de expresarse ${ }^{10}$. En (30), la producción de un alud de N2 se presenta como una estrategia a la que el Gobierno acude repetidamente, en ocasiones separadas. Parafraseando, se puede decir que la operación estratégica se presenta como una serie de componentes que forman una unidad con un punto inicial y un punto final bien definidos. Aluvión (de N2), en cambio, no va necesariamente delimitado claramente en el tiempo. En (31), los indicios mientras tanto y continúa sugieren un proceso en desarrollo. En (32), el intervalo se extiende sobre varios días, o sea, un período relativamente largo y el contexto sugiere que las llamadas continuaron los días siguientes.

(29) Se da la circunstancia de que la entrevista publicada ayer fue concedida a «ABC» el sábado, el mismo día que el magistrado decidió no llevar a cabo una rueda de prensa que él mismo había convocado en la Audiencia Nacional, tras el alud de críticas producido contra él la semana pasada. (CREA)

(30) El proceder seguido por el Gobierno es el de producir un alud de supuestos desmentidos y acusaciones de falsedad, formulados en un tono de aparente firmeza para crear confusión. En unos casos, refuta detalles nimios y en otros, da muestras de clara mala fe. (CREA)

(31) Mientras tanto, continúa el aluvión de mamíferos clonados o de experimentos con clones. (CREA)

10. La preposición tras corrobora la efectividad de las críticas y el complemento la semana pasada indica que cesaron después. 
(32) Los primeros días de enero, fue tal el aluvión de llamadas que sufrió dicha compañía, que llegaron a puntas de 100.000 llamadas en un día, con una media de más de 40.000. (CREA)

El parentesco etimológico entre alud y aluvión que se ve reflejado en las convergencias/divergencias de sus imágenes conceptuales se traduce también en las combinatorias encontradas. La Tabla 2 agrupa en cinco conglomerados semánticos los predicados verbales que se combinan frecuentemente con aludl aluvión. La tabla se lee de la manera siguiente: en el corpus sincrónico, alud va acompañado en 5 ocurrencias de un verbo que indica la recepción de N2 (p.ej. el alud de críticas que recibió $X$ ). Por razones de claridad, los predicados registrados no han sido listados exhaustivamente (salvo recibir en el caso de alud de).

\begin{tabular}{|c|c|c|}
\hline Verbos & Alud de & Aluvión de \\
\hline recepción & $\begin{array}{l}\text { (Total: 5) } \\
\text { recibir }\end{array}$ & $\begin{array}{l}\text { (Total 12) } \\
\text { recibir, conocer }\end{array}$ \\
\hline $\begin{array}{r}\text { provocación o } \\
\text { desencadenamiento }\end{array}$ & $\begin{array}{l}\text { (Total: 12) } \\
\text { provocar, producir, ocasionar, disparar, } \\
\text { desatar, descarga, lanzar }\end{array}$ & $\begin{array}{l}\text { (Total: 10) } \\
\text { provocar, atraer, levantar, ofrecer }\end{array}$ \\
\hline reacción & $\begin{array}{l}\text { (Total 5) } \\
\text { (no) frenar, compensar, ceder el paso a, } \\
\text { (no) soportar, (no) aguantar }\end{array}$ & $\begin{array}{l}\text { (Total: } 19) \\
\text { reaccionar, volier a la carga, } \\
\text { enfrentarse, atender, parar }\end{array}$ \\
\hline $\begin{array}{l}\text { causa/efecto de } \\
\text { fuerte imposición }\end{array}$ & $\begin{array}{l}\text { (Total: } 17) \\
\text { obliga, quedar + ADJ/PART, bacer } \\
\text { que +INF, afectar }\end{array}$ & $\begin{array}{l}\text { (Total: 8) } \\
\text { hacer, quedar + ADJ/PART, } \\
\text { impedir, venir determinado por }\end{array}$ \\
\hline $\begin{array}{r}\text { faceta del } \\
\text { semantismo } \\
\text { original de N1 }\end{array}$ & $\begin{array}{l}\text { (Total: 12) } \\
\text { colapsarse, bundir, caer, volcar sobre, } \\
\text { invadir }\end{array}$ & $\begin{array}{l}\text { (Total: } 25 \text { ) } \\
\text { sobrecargar, llenar, verterse sobre, caer } \\
\text { sobre, venir encima a, sobrevenir, } \\
\text { invadir, inundar, perturbar }\end{array}$ \\
\hline
\end{tabular}

Tabla 2. - Conglomerados de verbos asociados con los usos funcionales de aluvión de $y$ alud de en el corpus analizado.

Nótese primero que hay un considerable traslapo: ambos NCs ocurren fácilmente con verbos que denotan la recepción de N2, con verbos que remiten a la fase inicial, con verbos que indican la reacción de la víctima, con verbos que describen las consecuencias radicales y con verbos que reflejan la metáfora subyacente. Sin embargo, también se dan ciertas divergencias entre alud y aluvión. Tanto en el grado de proporcionalidad por grupo de verbos como respecto de los lexemas preferidos por grupo. Aunque no se puede ver en la Tabla 2, las combinaciones más frecuentes son recibir un aludlaluvión de N2 (respectivamente 5 y 10 ocurrencias en el corpus) y provocar un aludlaluvión de N2 (respectivamente 8 y 4 ocurrencias). A la luz del papel primordial de la causa identificable en la imagen conceptual de alud, es lógico que el conglomerado de verbos de desencadenamiento presente más variación léxica que en el caso de aluvión. Dado que un alud de N2 tiende a percibirse como más decisivo 
y contundente, no extraña la proporción más alta de verbos que apuntan al efecto drástico provocado por la llegada de N2. El que la víctima de un aluvión de N2 se conceptualice como un antagonista no desprovisto de recursos se refleja en el tipo de verbos de reacción: volver a la carga, enfrentarse, atender y parar sugieren que la entidad afectada no se deja vencer fácilmente. Con alud se corrobora la tendencia inversa, en particular por la frecuente asociación con la pseudocopulativa quedar(se) y adjetivos/participios que destacan la debilidad de la víctima (p.ej. sepultado, inundado, preocupado, paralizado, etc.).

La distribución de los $\mathrm{N} 2$ s que se combinan con aludy aluvión, reproducida en la Tabla 3, respalda observaciones similares. Como en el caso de los predicados verbales, los N2s se dejan agrupar en conglomerados semánticos. Las reacciones verbales son emblemáticas tanto de alud como de aluvión; críticas es la combinación preferida de ambos NCs (4 casos de alud, 13 de aluvión). A la luz del antagonismo que caracteriza la imagen de alud, no extraña que en la gran mayoría de los casos este $\mathrm{N} 1$ se combine con reacciones negativas como protestas, insultos, blasfemias, etc. mientras que aluvión admite también N2s de connotación positiva. En el caso de alud, el segundo rango es ocupado por acciones o productos políticos/económicos ${ }^{11}$; en el caso de aluvión lo es por personas que invaden el dominio de la víctima.

\begin{tabular}{|c|c|c|}
\hline N2 & Alud de & Aluvión de \\
\hline reacciones verbales & $\begin{array}{l}\text { (Total } 19) \\
\text { llamadas, carrajadas } \\
\text { negativas: }(15 / 19) \text { bipocresias, } \\
\text { insulios, criticas }\end{array}$ & $\begin{array}{l}\text { (Total } 49) \\
\text { llamadas, cartas, palabras } \\
\text { negativas: }(24 / 49) \text { criticas, quejas, } \\
\text { protestas }\end{array}$ \\
\hline gente & $\begin{array}{l}\text { (Total: 4) } \\
\text { clientes, tios y tias, corresponsales }\end{array}$ & $\begin{array}{l}\text { (Total: 21) } \\
\text { enfermos, colonizadores, turistas, } \\
\text { extranjeres }\end{array}$ \\
\hline $\begin{array}{l}\text { (fuentes de) } \\
\text { información }\end{array}$ & $\begin{array}{l}\text { (Total: } 10) \\
\text { noticias, propaganda, informaciones }\end{array}$ & $\begin{array}{l}\text { (Total } 7 \text { ) } \\
\text { datos, documentos, paginas neb }\end{array}$ \\
\hline $\begin{array}{l}\text { acciones o productos } \\
\text { (políticos/económicos) }\end{array}$ & $\begin{array}{l}\text { (Total: } 14) \\
\text { pactos, probibiciones, demandas, } \\
\text { normas } \\
\text { dinero: }(1 / 14) \text { dinero }\end{array}$ & $\begin{array}{l}\text { (Total: } 29) \\
\text { productos, ofertas, proyectos, elecciones, } \\
\text { cambios } \\
\text { dinero: }(4 / 29) \text { dinero, anticipos, } \\
\text { fondos }\end{array}$ \\
\hline $\begin{array}{r}\text { nociones abstractas } \\
\text { (generalmente } \\
\text { experiencias) }\end{array}$ & $\begin{array}{l}\text { (Total: } \theta) \\
\text { ideas, miradar, voces, imaigenes, } \\
\text { sentimientos }\end{array}$ & $\begin{array}{l}\text { (Total: 5) } \\
\text { pensamiento, bermosura }\end{array}$ \\
\hline otros & (Total: 12) & (Total: 21) \\
\hline
\end{tabular}

Tabla 3. - Conglomerados de N2s observados en los usos funcionales de aluvión de y alud de en el corpus analizado.

11. Dado que tanto la política como la economía son dominios con participantes que ocupan posiciones diametralmente opuestas, donde las acciones y reacciones suelen precipitarse y traer consecuencias impactantes para gran parte de la población, es lógico que estos contextos favorezcan el uso de alud y aluvión. 
Fuera del contexto de aludlaluvión de, no existe conexión lógica entre los distintos grupos de predicados verbales, ni entre los conglomerados de $\mathrm{N} 2 s$. Todos, sin embargo, hacen eco a algún componente de los dominios conceptuales asociados a los NCs. Así, por su significado léxico (e.g. turistas, inmigrantes, extranjeros) o el tipo de actualización en el contexto (véase infra, sección 3), todas las entidades N2 humanas se perciben como entidades que invaden el dominio de otro.

\subsection{Reflejos formales de la persistencia conceptual en la combinatoria de los NCs}

Además de las tendencias observadas en la combinatoria de NCs individuales, la persistencia conceptual se refleja también en las restricciones morfosintácticas que rigen el uso de los cuantificadores binominales: en tres aspectos por lo menos, la persistencia formal de la construcción parece ser conceptualmente motivada. Por razones de espacio, los párrafos siguientes resumen las principales conclusiones del análisis morfosintáctico comentado detalladamente en Verveckken (2012a). La atención se detiene sucesivamente en el determinante de N1 (2.2.1), los adjetivos susceptibles de modificar N1 (2.2.2) y la concordancia verbal (2.2.3).

\subsubsection{El determinante de $\mathrm{N} 1$}

Por el papel de cuantificador atribuido al NC en los usos cuantitativos -recuérdese que en los usos funcionales, N2 cumple el papel de núcleo sintáctico-, lo esperable es que no hubiera variación paradigmática del determinante de N1. La distribución de los determinantes por tipo de uso y generalizando sobre los NCs individuales, se presenta en la Tabla 4. La variación observada invita a hacer dos observaciones, una relativa al predominio del artículo indefinido, otra respecto de los casos con demostrativos.

En primer lugar, queda claro que el artículo indefinido es el determinante canónico en los tres usos: su frecuencia, algo superior al $65 \%$, contrasta con la marginalidad de los demás determinantes definidos, a saber, el artículo definido (32), el demostrativo (33) y el posesivo (34). El análisis cualitativo de las ocurrencias muestra, sin embargo, que la variación es conceptualmente motivada: en efecto, los determinantes definidos solo ocurren en las construcciones binominales topicalizadas. Es revelador también que en estos contextos se mantengan los mismos determinantes al omitir el NC, como se ve en (35). La preferencia por el artículo indefinido un(a) se ve además motivada por razones discursivas: corre parejas con el valor remático típicamente asociado al cuantificador binominal (cf. Mihatsch 2016: 146).

(33) No contenta con el éxito inicial, Editorial Office volvió a la carga y siguió bombardeando infructuosamente a Quintela con sucesivas ofertas de trofeos 
los ańos 1985, 1986 y 1987. (...). Abrumado por este alud de ofrecimientos, Quintela pasó al contraataque en clave de humor. (CREA)

(34) Ella lo recriminaba todavía, a la menor oportunidad, por lo que consideraba su cobardía para haberse lanzado a esa vorágine, su incapacidad para haber resuelto debidamente la situación. Esta tarde ha tenido que oírle de nuevo todas esas quejas, soportar su letanía de agravios y rencores, tratar de contestarle a preguntas que no tienen contestación, dulcificar respuestas que podrían resultar hirientes y que la hubieran exasperado más. (CREA)

(35)... Abrumado por estos ofrecimientos, Quintela...

... todas esas quejas, soportar sus agravios y rencores, ...

Tabla 4. - Distribución global de la variación del determinante por uso en el corpus analizado. En segundo lugar, la Tabla 4 muestra que los demostrativos aquel, ese y este se dan esencialmente en el uso categorizador. Cabe invocar otra vez motivos pragmático-discursivos: en este uso, el NC funciona antes que nada como categorizador y se apoya a menudo en la perspectiva subjetiva del enunciador. Además de los usos deícticos situacionales, el demostrativo puede, en efecto, revelar el involucramiento experiencial o epistémico del enunciador (cf. Delbecque 2011; 2013): en (36), aunque ese puede funcionar como marcador deíctico situacional y sugerir que el enunciador está seńalando un determinado conjunto de bandidos, se destaca más, en tales casos, su compromiso epistémico con la categorización. Y con entidades N2 abstractas que excluyen todo tipo de anclaje espacial, como en (37), esta indica que el enunciador está afectado en persona y que la categorización poco convencional de una larga serie de desgracias se origina en su dominio experiencial, adoptando su perspectiva.

(36) No pierdas tiempo en maldiciones. Enfílame a ese racimo de bandidos y pon tu pincho al servicio del rey. (CREA)

(37) ¿Por qué no me matas, Fernando, y acabamos de una vez con esta letanía de angustias y de lágrimas? (CREA)

En otras palabras, aunque marginal, la variación paradigmática del determinante es funcional y se explica por la integración discursiva del cuantificador binominal.

\subsubsection{El adjetivo modificador de N1}

Bajo el supuesto de que en la función cuantificadora el determinante, el NC y la preposición de forman un conjunto, tampoco se espera mucha variación en el paradigma adjetival. El análisis del corpus comprueba en efecto que el paradigma de los adjetivos observados no es abierto ni productivo, sino condicionado por restricciones formales y conceptuales. En (38), por ejemplo, resulta fácil añadir adjetivos como verdadero e imparable ya que intensifican la interpretación cuantitativa. En cambio, el NC no admite ni adjetivos relacionales (e.g. local) ni descriptivos (e.g. acuoso). 
(38) Recibí un [verdadero/imparable] alud de llamadas.

* Recibí un local alud de llamadas.

${ }^{*}$ Recibí un acuoso alud de llamadas.

Además, el uso de adjetivos intensificadores queda restringido a la posición prenominal ${ }^{12}$ : en el corpus no se dan combinaciones del tipo 'un alud verdadero de llamadas. Esta tendencia tiene una fácil explicación funcional y conceptual: la anteposición del adjetivo presenta la propiedad atribuida al nombre como conocimiento irrefutable y presuposicional ${ }^{13}$, mientras que la posposición invita a comparar el nombre modificado con otros miembros de su categoría en función de la característica expresada por el adjetivo (Delbecque 1990: 374-376). Por eso sería muy marcado el orden inverso: 'un alud imparable de llamadas, por ejemplo, hasta cierto punto implicaría la comparación externa con aludes distintos (e.g. (39)). La anteposición del adjetivo es pues la opción no marcada, y la única opción posible en los usos funcionales, ya que en estos $\mathrm{N} 1$ no tiene valor de referente, por lo cual queda excluida la posibilidad de una comparación externa.

(39) Recibí un inmenso alud de llamadas.

*Recibí un alud inmenso de llamadas.

$><$ Un alud inmenso (de nieve) aplastó los alpinistas.

Cabe insistir también en que los pocos adjetivos encontrados tienen una función bien específica: intensificar la cantidad implicada (e.g. grande), destacar la autenticidad (e.g. verdadero) o perfilar una determinada faceta de la imagen conceptual, presentándola -en anteposición- como la característica esencial de N1. De ahí que la lista de adjetivos posibles sea altamente previsible y relacionada al NC. Por ejemplo, en CREA, alud se combina exclusivamente con imparable, incontenible, rico, riquisimo, todo y verdadero. Es revelador además el carácter rebuscado de la combinación de otros NCs -salvo los cuasi-sinónimos aluvión y avalancha-con adjetivos como imparable o incontenible que tienen su anclaje en el espacio mental de alud.

\subsubsection{La concordancia verbal}

La concordancia verbal es el tercer tipo de variación que refleja el impacto que tiene la persistencia conceptual. Se aplica a los casos en que el cuantificador binominal desempeña el papel de sujeto. Tanto la tradición hispánica como la anglosajona señalan que el verbo concuerda necesariamente con el núcleo de la construcción binominal (véase también Keizer 2007; Traugott 2008; Vos

12. Los raros adjetivos pospuestos son en realidad participios complementados que necesariamente ocupan la posición posnominal (Delbecque 1990: 384). E.g. Para entonces el campamento ya sólo era un montón de escombros, rodeado de enemigos por todas partes.

13. Esta interpretación recuerda el principio cognitivo de la iconicidad, ya que "the processing of the given property is completed when 'arriving' at the noun" y así "the idea of any external comparison is overridden." (Delbecque 1990: 372). 
2002). Bajo este supuesto, en el caso de que el $N 2$ vaya en plural, la concordancia con N2 en plural indica que N2 funciona como núcleo y que N1 cumple la función de cuantificador, como en (40). En cambio, la concordancia con N1 en singular señala que el NC funciona como núcleo semántico y sintáctico de la construcción, como en (41). En tales casos, se activa el significado literal de N1.

(40) Cuando Mossén Ballarín (Barcelona, 1920) sale de los estudios de televisión donde ha sido entrevistado, un aluvión ${ }_{\mathrm{sg}}$ de $^{\text {personas }}{ }_{\mathrm{pl}}$ se le $\operatorname{acercan}_{\mathrm{pl}}$. Le han $\mathrm{pl}_{\mathrm{pl}}$ reconocido.

(41) La despertó sg $_{\mathrm{sg}}$ un alud de piedras $_{\mathrm{pl}}$. Como si derribaran la torre del homenaje. Pero era la comadre que había abierto la puerta, toda desgreńada y aventada.

Bien es cierto que, en CREA, la concordancia en plural se manifiesta mayoritariamente en los usos cuantitativos. Sin embargo, también se dan casos en que es manifiesta la interpretación cuantitativa sin que esto desencadene automáticamente la concordancia con N2 en plural. Verveckken \& Cornillie (2012) sugieren que, en tales casos, la razón por la concordancia con N1 debe buscarse en la persistencia conceptual: en ejemplos como (24) y (42), el singular aparece en contextos altamente metafóricos que explotan varias dimensiones de la imagen conceptual de aluvión. En (24), las actividades irrumpen por distintos frentes y con impetu después de la tregua veraniega. En (42), el aluvión de modelos nuevos es imparable (no ha impedido), continúa (siguen empeñados) y ocupa todos los huecos. El perfil de N1 se ve realzado además por el artículo definido en (24) y el adjetivo intensificador auténtico en (42).

(42) La incertidumbre no ha impedido que en Ginebra saliera $\mathrm{sg}_{\mathrm{g}}$ a la luz un auténtico aluvión $\mathbf{s}_{\mathrm{sg}}$ de modelos $_{\mathrm{pl}}$ nuevos: las marcas siguen empeñadas en ocupar todos los huecos del mercado para ampliar las ventas y no dar ventajas a la competencia.

En otras palabras, en ambos contextos la imagen del aluvión literal persiste en el uso cuantitativo hasta tal punto que la concordancia con N1 vuelva a ser la opción menos marcada. Dicho de otro modo, la concordancia en singular con N1 corre parejas con un alta grado de persistencia léxica y es poco probable en contextos donde la metáfora queda menos visible, como en (40).

\section{LOS CUANTIFICADORES BINOMINALES COMO RECURSO DE COHERENCIA}

Si cada NC impone su propia conceptualización de las entidades N2, como acabamos de ver en los apartados anteriores, cabe verificar en qué medida la persistencia conceptual motiva la variación en el paradigma de N1 y enlaza con su valor pragmático.

La reflexión que se desarrolla a continuación se apoya en la noción de 'isotopía' (Kerbrat-Orecchioni 1979, Rastier 1987). En el marco de la semántica estructuralista francesa, este término se refiere a la coocurrencia de lexemas 
del mismo campo semántico en un mismo texto. En términos de análisis discursivo, la idea subyacente es que el enunciador siempre procura construir un universo con elementos congruentes y ser máximamente coherente en su discurso. A la luz de este principio se postula en esta sección que la persistencia conceptual interactúa con la integración discursiva (la "mise en discours") del NC y constituye un fenómeno bi-direccional. Así, en la construcción de un universo coherente, el enunciador puede optar por un determinado NC en función de la coherencia de su discurso.

Como se desprende de lo anterior, N1 impone su imagen conceptual a N2. La descripción de las imágenes conceptuales de alud y aluvión (Sección 2.1) ha mostrado además que, en función de su estructura esquemática, los N1s desarrollan preferencias combinatorias (en particular con respecto a N2). Por ejemplo, dado el semantismo original de hatajo - una manada de ovejas que carecen de individualidad, guiadas por su instinto - no es de extrañar que el cuantificador hatajo de se combine de preferencia con referentes humanos menospreciados por el enunciador. De modo similar, las combinatorias preferidas de los demás NCs analizados hacen eco al semantismo original de N1: letanía de evoca la repetitividad en una serie de palabras o discursos; pila de se combina de preferencia con objetos apilables, en general de papel (como libros, hojas, revistas, etc.) y por extensión metafórica con unidades temporales ordenables cronológicamente (como años, días, etc.); montón de no evoca nada más que un conjunto desordenado y se asocia preferentemente con el N2 cosas, al que suele corresponder una conceptualización vaga y camaleónica. En términos generales, se puede decir que la restricción mínima que impone cada $\mathrm{N} 1$ a N2 es que las entidades N2 sean compatibles - por su significado léxico o por la integración discursiva - con la imagen conceptual de N1.

Ahora bien, la cuestión es más compleja y requiere que se aborde también el papel que N2 desempeña en la selección de N1. Resulta que no es solo la imagen de N2 la que se acomoda a la imagen conceptual introducida mediante N1, sino que la acomodación va en ambas direcciones: se opera un ajuste mutuo entre las imágenes asociadas a N1 y N2. Puesto que en los usos funcionales N2 desempeña el papel de núcleo y proporciona la información esencial, en el contexto más amplio el perfil de N2 es más prominente que el de N1. Es reveladora al respecto la estabilidad con que determinados N2s se combinan de preferencia con un determinado N1 o con un determinado tipo de N1 (sin dar lugar necesariamente a expresiones semi-lexicalizadas como un enjambre de abejas). Así, sustantivos como criticas, llamadas, protestas, etc., que por definición remiten a entidades que emergen como re-acciones negativas, tienden a combinarse con NCs como alud o aluvión. Nótese que la combinación de críticas con hatajo, letanía, tropel, racimo y pila no se da en CREA. Además, para la secuencia 'de criticas', CREA casi exclusivamente depara combinaciones con fenómenos naturales aplastantes como aluvión, alud, lluvia, avalancha, torrente, ola, oleada, chaparrones, tormenta y marejada. Para la secuencia 'de preguntas', CREA da batería de preguntas como colocación preferida (25 casos, 
al lado de cuantificadores propiamente dichos o NCs generales como serie (63 casos) o par (15 casos). Además, los N1s que introducen el sintagma preposicional 'de preguntas' pertenecen casi exclusivamente a uno de los cuatro conglomerados semánticos siguientes: evocan una imagen de alineamiento horizontal (e.g. retahila, sarta, madeja, cadena), de ataque violento (tiroteo, bombardeo, andanada), de fenómenos naturales dinámicos que rebasan todo control humano (mar, ola, chaparrón, avalancha, aluvión) o de caos (montón, laberinto, maraña). Estos N1s no por casualidad destacan la índole implacable, imparable, confusa, a menudo antagónica e incluso agresiva del N2 'preguntas'. Huelga decir que no todos los $\mathrm{N} 2 \mathrm{~s}$ se caracterizan por preferencias combinatorias tan marcadas: sustantivos que carecen de connotación emotiva o nombres poco específicos como personas, que solo evocan marcos generales, se combinan con un abanico más amplio de NCs. Consta, sin embargo, que, en general, los N2s tienden a combinarse con nombres capaces de evocar imágenes conceptuales que maximizan los rasgos correspondientes.

La acomodación mutua trasciende además los contornos del sintagma binominal. Como en el contexto suelen presentarse varios indicios que realzan la persistencia de N1 en la cuantificación de N2 (véase supra, Sección 2) ${ }^{14}$, conviene incluir también el nivel del contexto más amplio. La idea es que la coocurrencia de elementos léxicos que comparten una o varias facetas conceptuales con $\mathrm{N} 1$ aumenta la prominencia relativa que tienen estos componentes en el marco ("frame"15) evocado por el discurso más amplio. En otras palabras, N2 y el contexto más amplio co-determinan la (selección de) faceta(s) de la imagen conceptual de N1 que se actualiza(n) en ocurrencias concretas.

Así, en función de la acomodación mutua entre el N1 por un lado, y el N2 y el contexto más amplio por otro, la selección de N1 puede servir de recurso de coherencia conceptual. Desde un punto de vista discursivo, es el perfil de N2 el que el enunciador quiere destacar y que guía la selección del NC apropiado, y no al revés. Los ejemplos dados a continuación ilustran la acomodación conceptual al nivel discursivo. Mientras que, fuera de contexto, parece rebuscada la combinación de aluvión de con la entidad nominal inerte páginas web, en (43) aluvión resulta convenir muy bien a la luz de los indicios contextuales (en bastardilla): la aparición repentina de las páginas web nuevas se presenta como el reflejo del boom considerable de las medicinas alternativas que se produce en varias regiones del país. Estas características, atribuidas a las páginas web por la escena evocada en el contexto, coinciden fundamentalmente con el semantismo original de aluvión: este $\mathrm{NC}$ es pues máximamente coherente en este contexto particular. Se puede afirmar que el semantismo original de N1 interactúa

14. Recuérdese que la co-ocurrencia de indicios contextuales es uno de los criterios para elaborar las imágenes conceptuales propias de los NCs. El caso de aludlaluvión ha mostrado además que incluso al nivel del predicado verbal, los NCs pueden presentar tendencias combinatorias que les son propias.

15. En la teoría conocida como "frame semantics" toda unidad léxica va asociada a un conjunto de conocimientos culturales, experiencias y creencias propias de la comunidad en que se emplea (véase Fillmore 1982). 
con el discurso más amplio y contribuye a la congruencia semántica. Aunque en la mayoría de las ocurrencias es posible insertar varios NCs formalmente aceptables, cada contexto particular privilegia un determinado NC por ser más conveniente y coherente. En (44), barbaridad es muy apropiado como NC: (i) varios indicios - abusiva, afrenta, no debian ser, etc. - remiten a un exceso o una infracción a una norma social; (ii) etimológicamente, barbaridad proviene del vocablo 'bárbaro' que en la antigüedad clásica designaba a los extranjeros, a menudo considerados incivilizados. El contexto de (44) evoca las dificultades de un turista para adaptarse a las normas londinenses. Aunque la coherencia es particularmente alta en este ejemplo, huelga decir que nuestro análisis no supone que los hablantes nativos conozcan la etimología.

(43) Tras arrasar en Estados Unidos, la medicina alternativa extiende sus tentáculos en Espańa. (...) Al otro lado del Atlántico, el boom es de tal calibre que en algunas zonas del país cerca del $50 \%$ de los pacientes recurre a estas prácticas. (...) Como era de esperar, Internet también refleja este interés social, con un verdadero aluvión de páginas web sobre muchas de las medicinas alternativas.

(44) Pagó a regañadientes la abusiva nota del té completo dejando incluso una propina excesiva para aliviar de algún modo la afrenta de aquella situación. Pansy le regañó al salir. En la guía Fodor's había leído que las propinas en Londres no debian ser superiores en ningún caso al 15 por ciento suponiendo que no estuviera ya incluida en la factura. Y él había dejado una barbaridad de propina que podría haberse destinado a la compra de otra jarrita del té (...).

La Figura 5 representa el ajuste bi-direccional entre N1, por un lado, y N2 y el contexto más amplio por otro. Por la iconicidad del orden lineal, N1 impone su imagen conceptual a N2 y desarrolla así preferencias combinatorias. A su vez, N2 y el contexto más amplio guían la selección del NC apropiado y determinan la selección de faceta(s) conceptual(es) que se actualiza(n) en ocurrencias particulares.

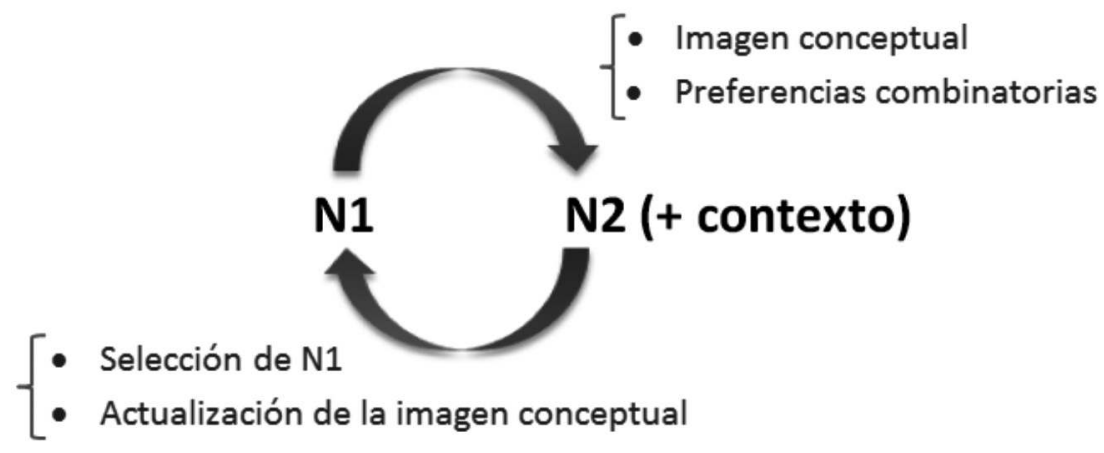

Figura 5. - Acomodación mutua entre N1 y N2/contexto más amplio. Visualización de la interfaz esbozada por las autoras. 
El mecanismo de adaptación mutua puede formularse en los términos de la semántica de marcos (Fauconnier \& Turner 1998, Sweetser 1999): los espacios mentales - o imágenes conceptuales - de N1, de N2 y del contexto más amplio, se funden en un solo marco convergente (el llamado "blend"). En otras palabras, la imágenes originales se proyectan solo parcialmente en el marco (o "frame") final: en la conceptualización final, solo se traslucen las facetas conceptuales de N1 que se ajusten al marco de N2, y al revés. De ahí que la interpretación final de los cuantificadores binominales dependa del contexto concreto (cf. el carácter emergente del significado).

\section{Conclusiones}

En último resorte, la amplia variación en el paradigma de los NCs se explica por su valor pragmático: al imponer su propia conceptualización de la masa N2, los NCs constituyen cuantificadores expresivos que contribuyen a la coherencia del discurso. La sustitución de un NC por otro - incluso en el caso de cuasi-sinónimos como alud y aluvión - entraña un deslizamiento semántico sutil en ocurrencias concretas. El concepto clave es la 'persistencia conceptual': los usos funcionales del NC dejan entrever varias facetas de su semantismo original. Más allá de las combinatorias propias que los NCs desarrollan en función de su imagen conceptual individual, el impacto de la persistencia conceptual se observa al nivel de las restricciones morfosintácticas de la construcción binominal.

$\mathrm{Al}$ enlazar con dos nociones utilizadas frecuentemente en el marco de la gramaticalización, el análisis propuesto apunta a por lo menos dos repercusiones teóricas. En primer lugar, los resultados sugieren que el concepto de 'persistencia léxica' (Hopper 191) merece ser interpretado en sentido menos estricto como un fenómeno más bien conceptual y gradual, que interactúa además con el contexto discursivo. En segundo lugar, el tema enlaza con el concepto de 'analogía' (Traugott \& Trousdale 2010, De Smet 2013) tradicionalmente confinado a la dimensión paradigmática y semejanzas estrictamente formales. El análisis sugiere que para explicar la variación en el paradigma del NC, no basta examinar aisladamente el $\mathrm{N} 1$ en el sintagma, sino que hace falta incluir también el papel de $\mathrm{N} 2$ y del discurso más amplio.

\section{Referencias bibliográficas}

Bosque Ignacio, «Procesos de abstracción en los paradigmas léxicos abiertos», Pandora: revue d'études hispaniques, 2007, 7, p. 189-198.

Bosque Ignacio y Violeta Demonte (dirs.), Gramática descriptiva de la lengua española, Madrid, Espasa-Calpe, 1999.

Brucart José Maria, «Concordancia ad sensum y partitividad en español», en Almeida Manuel y Dorta Josefa (eds.), Contribuciones al estudio de la lingüistica hispánica. 
Homenaje al profesor Ramón Trujillo, 1, Tenerife, Montesinos, 1997, p. 157-183.

Delbecque Nicole, "Word order as a reflection of alternate conceptual construals in French and Spanish. Similarities and divergences in adjective position", Cognitive Linguistics, 1990, 1, 4, p. 349-416.

Delbecque Nicole, «Los usos no situacionales de los demostrativos españoles: enfoque cognitivo», en Sinner Carsten, Wotjak Gerd y Hernández Socas Elia (eds.), Estudios de tiempo y espacio en la gramática española, 78, Bern, Peter Lang, 2011, p. 155-174.

Delbecque Nicole, "Anclaje experiencial y epistémico de los demostrativos no situacionales en español», Anuario de Letras, 2013, I, 2, p.85-168.

Delbecque Nicole y Verveckken Katrien, "Conceptually driven analogy in the grammaticalization of binominal quantifiers», Linguistics, 2014, 52, 3, p. 637-684.

De Smet Hendrik, Spreading patterns: Diffusional change in the English system of complementation, Oxford Studies in the History of English, New York, Oxford University Press, 2013.

Dirven René y Verspoor Marjolein (eds.), Cognitive Exploration of Language and Linguistics, Amsterdam-Philadelphia, John Benjamins Publishing Company, 1998.

García Érica C., The motivated syntax of arbitrary signs. cognitive constraints on Spanish clitic clustering, Studies in Functional and Structural Linguistics 61, AmsterdamPhiladelphia, John Benjamins, 2009.

Fauconnier Gilles y Turner Mark, "Conceptual integration networks», Cognitive Science, 1998, 22, p. 133-187.

Fillmore Charles J. «Frame semantics», Linguistics in the Morning Calm, Seoul, Hanshin, 1982, p. 111-137.

Hopper Paul J., «On some principles of grammaticization», en Traugott Elisabeth Closs y Heine Bernd (eds.), Approaches to Grammaticalization. Volume I: Focus on theoretical and methodological issues, Amsterdam-Philadelphia, John Benjamins, 1991, p.17-36.

Keizer M. Evelien, The English noun phrase: the nature of linguistic categorization, Cambridge, Cambridge University Press, 2007.

Kerbrat-Orecchioni Catherine, De la sémantique lexicale à la sémantique de l'énonciation, Lille, Service de reproduction des thèses, 1979.

Maldonado González Concepción, Clave: diccionario de uso del español actual, 3era edición. [En línea]. Ediciones SM, 1999. http://clave.librosvivos.net/

Mihatsch Wiltrud, "Type-noun binominals in four Romance languages», en Brems Lieselotte, De Clerck Bernard \& Verveckken Katrien (eds.), Binominal syntagms as loci of synchronic variation and diachronic change, Special issue of Language Sciences, 2016, 53, part B, p. 136-159.

Moliner María. Diccionario de uso del español, 3era edición. [CD-Rom]. Madrid, Gredos, 2008.

Paradis Carita, "Metonymization: A key mechanism in semantic change», en Barcelona Antonio, Benczes Réka y Ruiz de Mendoza Ibáńez Francisco José (eds.), Defining Metonymy in Cognitive Linguistics. Towards a consensus view, AmsterdamPhiladelphia, John Benjamins, 2011, p. 61-88. 
Pottier Bernard, «L'isosémie lexico-grammaticale dans les textes», en Luquet Gilles (ed.), Travaux de linguistique hispanique, Paris, Presses de la Sorbonne Nouvelle, 1998, p. 401-408.

Rastier François, Sémantique interprétative, Paris, PUF, 1987.

Real Academia Española, Diccionario de la lengua española (DRAE), Vigésima segunda edición. [En línea]. http://www.rae.es, 2001.

Real Academia Española, Corpus de referencia del española actual. [En línea]. http:// www.rae.es.

Real Academia Española y Asociación de Academias de la Lengua Eespañola, Nueva gramática de la lengua española, Madrid, Espasa, 2009.

Sweetser Eve, "Compositionality and blending», en Janssen Theo y Redeker Gisela (eds.), Cognitive Linguistics: Foundations, Scope, and Methodology, Berlin, Mouton de Gruyter, 1999, p. 129-162.

Traugott, Elisabeth Closs. «Grammaticalization, constructions and the incremental development of language: Suggestions from the development of degree modifiers in English», en Eckardt Regine, Jäger Gerhard y Veenstra Tonjes (eds.), Variation, selection, development. Probing the evolutionary model of manguage change, BerlinNew York, Mouton de Gruyter, 2008, p. 219-250.

Traugott Elisabeth Closs y Trousdale Graeme, «Gradience, gradualness and grammaticalization. How do they intersect?», en Elisabeth Closs Traugott y Trousdale Graeme (eds.), Gradience, Gradualness and Grammaticalization, Amsterdam-Philadelphia, John Benjamins, 2010, p. 19-43.

Verveckken Katrien, The binominal quantifier construction in Spanish and conceptual persistence. A cognitive-functional analysis, Tesis doctoral, KU Leuven, 2012a.

Verveckken Katrien, «Towards a constructional account of high and low frequency binominal quantifiers in Spanish», Cognitive Linguistics, 2012b, 23, 2, p. 421-478. Vos Riet, "Las construcciones de cuantificador nominal en holandés y español», Foro Hispánico, 2002, 21, p. 47-58. 